\title{
Instantáneas sobre el derecho a la propia imagen. Un análisis de la legislación y jurisprudencia actual y el derecho comparado
}

\author{
$* * * *$ \\ Santiago Durañona \\ Profesional independiente en Estudio Ojam Bullrich Flanzbaum \\ sduranona@ojambf.com \\ Mariano Peruzzotti \\ Profesional independiente en Estudio Ojam Bullrich Flanzbaum \\ mperuzzotti@ojambf.com
}

Recibido: 29 de octubre de 2021

Aceptado: 23 de noviembre de 2021

\section{Resumen}

En el presente artículo se aborda el análisis del derecho a la imagen, considerando a tal efecto su evolución en diversos sistemas jurídicos para llegar a su actual concepción. Para ello, se toman en cuenta los caracteres, la legislación y la jurisprudencia. Principalmente, se toma como referencia el caso en la Argentina y luego se desarrolla su tutela en el derecho comparado, específicamente Estados Unidos, España y Portugal. Como se podrá observar a lo largo del trabajo, dependiendo del territorio en cuestión, el derecho a la imagen cuenta con diferente alcance y protección. A pesar de ello, corresponde destacar que ciertos elementos son comunes y se reiteran en una gran cantidad de jurisdicciones. En este sentido, las definiciones del derecho bajo estudio se fueron modernizando a lo largo del tiempo, adaptándose a los escenarios cambiantes que se han ido presentando. Vale señalar que el desarrollo de la tecnología ha tenido un impacto sustancial en este derecho, en especial por la proliferación de dispositivos accesibles al público que permiten la captación instantánea de imágenes que, a su vez, pueden ser reprodu- 
cidas inmediatamente y difundidas en forma masiva a cualquier parte del mundo. Ello ha dado surgimiento a un derecho que, como tantos otros, requiere de una regulación dinámica y adaptable a cada época.

Palabras clave: derecho a la imagen, derechos personalísimos, Argentina, derecho comparado, Estados Unidos, España, Portugal.

\title{
Snapshots on the Right to One's Own Image. An Analysis of Current Legislation, Caselaw and Comparative Law
}

\begin{abstract}
This article deals with the analysis of the right to the image, considering for this purpose its evolution in different legal systems to reach its current conception. To this end, the characters, legislation and jurisprudence are taken into account. Mainly, the case of Argentina is taken as a reference and then its protection in comparative law is developed, specifically in the USA, Spain and Portugal. As it will be exposed throughout the work, depending on the territory in question, the right to the image has different scope and protection. Nevertheless, it should be noted that certain elements are common and are reiterated in a large number of jurisdictions. In this sense, the definitions of the right under study have been modernized over time, adapting to the changing scenarios that have arisen. It is worth noting that the development of technology has had a substantial impact on this right, especially due to the proliferation of devices accessible to the public that allow the instantaneous capture of images that, in turn, can be immediately reproduced and massively disseminated to any part of the world. This has given rise to a right that, like so many others, requires a dynamic regulation that can be adapted to each era.
\end{abstract}

Key words: right to privacy, right of publicity, personal rights, Argentina, comparative law, United States, Spain, Portugal.

\section{Instantâneas à direito da própria imagem. Uma análise da legislação atual, jurisprudência e direito comparado}

\section{Resumo}

Este artigo analisa o direito à imagem, considerando sua evolução em diferentes sistemas legais para chegar à sua concepção actual. Para este fim, são tidos em conta os caracteres, a legislação e a jurisprudência. $\mathrm{O}$ caso da Argentina é tomado como referência e depois é desenvolvida a sua protecção em direito comparado, especificamente nos EUA, Espanha e Portugal. Como se verá ao longo deste do- 
cumento, dependendo do território em questão, o direito a uma imagem tem um âmbito e uma protecção diferentes. No entanto, vale a pena notar que certos elementos são comuns e são reiterados num grande número de jurisdições. Neste sentido, as definiçóes do direito em estudo foram sendo modernizadas ao longo do tempo, adaptando-se aos cenários de mudança que surgiram. Vale a pena notar que o desenvolvimento da tecnologia teve um impacto substancial neste direito, especialmente devido à proliferaçáo de dispositivos acessíveis ao público que permitem a captura instantânea de imagens que, por sua vez, podem ser imediatamente reproduzidas e massivamente difundidas em qualquer parte do mundo. Isto deu origem a um direito que, como tantos outros, requer uma regulaçáo dinâmica e adaptável aos tempos.

Palavras-chave: direito à imagem, direitos pessoais, Argentina, direito comparado, Estados Unidos, Espanha, Portugal.

\section{Introducción}

Se cree que los primeros razonamientos jurídicos en torno al derecho a la propia imagen se dieron con lo que fue la invención de la fotografía en el año 1824, cuando el químico francés Nicéforo Niepce realizó el primer procedimiento fotográfico o heliográfico, técnica que después fue perfeccionada por Luis Jacobo Mandé Daguerre (creador del daguerrotipo en 1839) (Rodrigues da Cunha e Cruz, 2009).

Esto se debe a que, con la invención de la fotografía y la posterior posibilidad de reproducir las copias, se permitió la multiplicación de las imágenes de las personas y, por consiguiente, su exposición de forma más reiterada y manifiesta. Esto generó la existencia de un riesgo de dańo a la personalidad por medio del abuso de la representación gráfica de la imagen humana, siendo necesario razonar jurídicamente en torno al derecho a la propia imagen (Rodrigues da Cunha e Cruz, 2009).

Fue así que comenzaron a surgir diversas concepciones del derecho a la imagen, que, conforme se desarrollará en el presente artículo, cuenta con diferente alcance y protección dependiendo del territorio en cuestión. A pesar de ello, corresponde destacar que ciertos elementos son comunes y se repiten en una gran cantidad de jurisdicciones.

En línea con lo anterior, las definiciones del derecho bajo estudio se fueron modernizando a lo largo del tiempo, adaptándose a los escenarios cambiantes que se han ido presentando. En tal sentido, el 
desarrollo de la tecnología ha tenido un impacto sustancial en este derecho, en especial por la proliferación de dispositivos accesibles al público que permiten la captación instantánea de imágenes que, a su vez, pueden ser reproducidas inmediatamente y difundidas en forma masiva a cualquier parte del mundo. Ello ha dado surgimiento a un derecho que, como tantos otros, requiere de una regulación dinámica y adaptable a cada época.

\section{Aproximación al concepto del derecho a la propia imagen}

A fin de llegar a una aproximación a la comprensión y alcance del derecho a la propia imagen, seguidamente haremos referencia a sus principales características. En primer lugar, podemos decir que surge del hecho mismo de considerar que el ser humano se encuentra en el mundo de forma corpórea o física. Esta realidad propia de la persona propicia una de las fuentes de datos e información más importante sobre los individuos, en tanto la figura humana como cara externa de la persona es susceptible de ser captada a través de distintos medios e instrumentos (Nogueira Alcalá, 2007).

Es importante señalar que solo se puede hablar de imagen, como objeto de protección jurídica, cuando se consigue percibir los rasgos particulares individualizadores de una persona humana, los que posibilitan la representación gráfica visible del aspecto físico externo de su figura. Por tanto, y a contrario sensu, la representación de una imagen no reconocible es lícita (Rodrigues da Cunha e Cruz, 2009) $y$, en principio, no se encuentra limitada por ninguna condición o autorización previa para su uso o reproducción. En este sentido, la toma de una foto difuminada por efecto de la mano del fotógrafo o producto de las herramientas técnicas -como el "blureo"- que den como resultado una imagen que de modo alguno permita la identificación del sujeto no estaría en principio alcanzada por este derecho. Sin embargo, es importante señalar que la existencia de algún elemento o acción que permita la asociación del retrato difuminado con la persona, aun cuando este no alcance un grado considerable de nitidez o precisión, podría ser objeto de protección.

Este derecho no se circunscribe al aspecto fisionómico de una persona, sino que el concepto abarca otros aspectos de la persona, 
como la voz, un gesto particular, una forma de vestir o actuar, un tic, una acción característica, etc. Se trata de cualquier aspecto exteriorizable de la persona que la haga reconocible ante terceros (Ceballos Delgado, 2011). Por ello, la protección comprende la imagen de la persona, sus rasgos, características, así como el contexto y las circunstancias que habilitan la identificación.

Seguidamente, los autores hacen referencia a la faceta dual del derecho a la imagen, la que incide en su definición. A tal efecto, para Manuel da Costa Andrade, el sentido de la propia individualidad crea dos perspectivas en la configuración jurídica de tal derecho: por un lado, una exigencia de circunspección, de reserva, de exclusión, que garantiza la inviolabilidad personal y, por el otro, establece la autonomía jurídica individual y la autodeterminación del individuo para proyectarse socialmente. Al titular le asiste, con exclusividad, el derecho de determinar quién puede representar, grabar, registrar, utilizar o divulgar su imagen (Andrade, 1996, como se citó en Rodrigues da Cunha e Cruz, 2009). A raíz de ello, se considera que existen dos facetas vinculadas a la imagen personal: una positiva, esto es, el derecho a que cada sujeto pueda captar y reproducir su propia imagen conforme a la autonomía de su voluntad, y otra negativa, que determina que pueda impedirse la difusión de la imagen de una persona sin su consentimiento expreso (Barbieri, 2014).

La faceta dual del derecho a la imagen ha sido reconocida en precedentes jurisprudenciales de nuestro país. En efecto, los jueces han dicho que

el derecho a la imagen es la facultad de cada persona de disponer exclusivamente de ella a través de la fotografía divulgada por los medios de comunicación masiva, como la prensa y la televisión, así como por el cinematográfico, y como consecuencia de ello, también consiste en el derecho a oponerse a que otro la utilice con cualquier fin. ${ }^{1}$

Dicho lo anterior, en los próximos apartados describiremos el régimen legal aplicable en Argentina, comentando la jurisprudencia

1 Cámara Nacional de Apelaciones en lo Civil, sala D, Maradona, Diego Armando c/Telecom Personal SA y otros s/daños y perjuicios, 26/06/2014. 
más reciente sobre este derecho para luego detenernos en el análisis de la regulación respectiva en otras jurisdicciones, tal como Estados Unidos (EE. UU.), España y Portugal.

\section{Régimen legal en Argentina}

En primer lugar, es importante destacar que, a diferencia de lo que ocurre con las constituciones de otros países como España, ${ }^{2}$ Portugal, $^{3}$ Brasil $^{4}$ y Perú, ${ }^{5}$ el derecho a la imagen no se encuentra mencionado de forma expresa en el texto de la Constitución Nacional Argentina. Sin embargo, dado que este derecho se encuentra comprendido dentro de aquellos derechos personalísimos que son manifestaciones espirituales de la persona de manera semejante al derecho al honor y a la intimidad, cierta parte de la doctrina considera que está contemplado de forma genérica en los artículos $19^{6}$ y 33 de la carta magna (Cabello, 2018).

En esta línea, cuando mediante la violación del derecho a la imagen se lesiona simultáneamente la intimidad de la persona retratada, entra en juego la garantía de reserva receptada en el artículo 19, parte primera, de la Constitución Nacional (1994), en cuanto se transgrede la inviolabilidad de la vida privada. En tal sentido, cabe recordar que la disposición establece que "[l] as acciones privadas de los hombres que de ningún modo ofendan al orden y a la moral pública, ni perjudiquen a un tercero, están sólo reservadas a Dios, y exentas de la autoridad de los magistrados.”

2 Constitución Española, artículos 18.1 y 20.4. Disponible en: https://www. boe.es/legislacion/documentos/ConstitucionCASTELLANO.pdf.

3 Constitución de la República Portuguesa, artículo 26.1. Disponible en: https://www.constituteproject.org/constitution/Portugal_2005.pdf?lang=es.

4 Constitución Política de la República Federativa del Brasil de 1988, artículos 5 V y X. Disponible en: https://www.acnur.org/fileadmin/Documentos/ BDL/2001/0507.pdf.

5 Artículo 2, numeral 7o de la Constitución Política del Perú. Disponible en: https://www.oas.org/juridico/spanish/per_res17.pdf.

6 Cámara Nacional de Apelaciones en lo Civil, Sala A, Alzugaray, Mirna Fernanda c/Taraborelli Automobile SA s/daños y perjuicios, 16/07/2021. AR/ JUR/106167/2021. 
Sumado a ello, también se entiende que el derecho a la propia imagen se encuentra comprendido en el artículo 33 de la Constitución Nacional, ya que este hace referencia a los denominados "derechos implícitos" o "derechos no enumerados", los cuales son consagrados en los siguientes términos: "Las declaraciones, derechos y garantías que enumera la Constitución no serán entendidos como negación de otros derechos y garantías no enumerados; pero que nacen del principio de la soberanía del pueblo y de la forma republicana de gobierno". Por ello, aun cuando el texto de la Constitución Nacional no lo haya consagrado expresamente, lo cierto es que el reconocimiento del derecho deviene de los principios e instituciones que son el espíritu del orden constitucional y democrático.

Por otro lado, el derecho a la imagen se encuentra regulado expresamente en otros cuerpos legales, como es la Ley 11723 de Propiedad Intelectual (LPI). En este sentido, este derecho fue reconocido en el artículo 31 cuando se sancionó la LPI en el ańo 1933 en los siguientes términos:

El retrato fotográfico de una persona no puede ser puesto en el comercio sin el consentimiento expreso de la persona misma y muerta ésta, de su cónyuge e hijos o descendientes directos de éstos, o en su defecto, del padre o de la madre. Faltando el cónyuge, los hijos, el padre o la madre, o los descendientes directos de los hijos, la publicación es libre.

La persona que haya dado su consentimiento puede revocarlo resarciendo daños y perjuicios.

Es libre la publicación del retrato cuando se relacione con fines científicos, didácticos y en general culturales, o con hechos o acontecimientos de interés público o que se hubieran desarrollado en público.

Posteriormente, y como consecuencia del proceso de constitucionalización del derecho privado (Cabello, 2018), el derecho a la imagen fue también reconocido por el nuevo Código Civil y Comercial de la Nación (CCyC), el cual fue promulgado en octubre de 2014 y que entró en vigencia el 1 de agosto de 2015. Específicamente, el artículo 53, que se encuentra dentro del capítulo referido a los 
"Derechos y actos personalísimos", adaptó las previsiones de la LPI como base y fuente. Tal disposición establece lo siguiente:

Derecho a la imagen. Para captar o reproducir la imagen o la voz de una persona, de cualquier modo que se haga, es necesario su consentimiento, excepto en los siguientes casos:

a) que la persona participe en actos públicos;

b) que exista un interés científico, cultural o educacional prioritario, y se tomen las precauciones suficientes para evitar un daño innecesario;

c) que se trate del ejercicio regular del derecho de informar sobre acontecimientos de interés general.

En caso de personas fallecidas pueden prestar el consentimiento sus herederos o el designado por el causante en una disposición de última voluntad. Si hay desacuerdo entre herederos de un mismo grado, resuelve el juez. Pasados veinte años desde la muerte, la reproducción no ofensiva es libre.

Particularmente, corresponde aclarar que la norma del CCyC no deroga lo dispuesto por la LPI, sino que, a través del artículo 53, complementa aquella actualizando el texto legal. ${ }^{7}$ Consecuentemente, en caso de existir diferencias o incompatibilidades entre ambos textos, el núcleo duro que conforma la LPI y el CCyC conducirá a una interpretación tendiente a garantizar una mayor protección al derecho e integral (Cabello, 2018).

Conforme se desprende de la redacción de los dos textos legales citados, existen notables diferencias entre ambos regímenes, siendo algunas de ellas sustanciales y de gran trascendencia. Por ello, a continuación las exponemos brevemente:

1. En primer lugar, debemos resaltar que el CCyC amplía el

7 Por su parte, el artículo 1770 del CCyC fortalece la protección al establecer que aquella persona que arbitrariamente se entrometa en la vida ajena y publique debe ser obligado a cesar en tales actividades, si antes no cesaron, y a pagar una indemnización que debe fijar el juez de acuerdo con las circunstancias. Además, a pedido del agraviado, puede ordenarse la publicación de la sentencia en un diario o periódico del lugar si esta medida es procedente para una adecuada reparación. 
contenido del derecho tutelado, ya que para dicha norma no solo comprende el aspecto físico de una persona, sino también la voz. Esto resulta adecuado y refleja la opinión casi unánime en la doctrina especializada, que sostenía que la protección de la LPI debía ser extendida a la voz, en cuanto constituye el reflejo sonoro de la imagen y configura, junto con esta, la identidad externa de una persona (Barbieri, 2014).

2. Otra diferencia es la que versa sobre el alcance del consentimiento otorgado por el sujeto para la difusión de su imagen. Anteriormente, conforme a una lectura textual de la LPI, la prohibición de reproducir la imagen del titular sin su consentimiento abarcaba únicamente aquellas que tenían fines comerciales. Este aspecto es omitido en la nueva norma, ya que ahora es necesario su consentimiento para captar o reproducir la imagen o la voz de una persona, de cualquier modo que se haga, excepto en los casos especialmente previstos. Por ello, la protección que brinda el derecho a la imagen según el artículo 53 del CCyC es más amplia que la protección que brinda el artículo 31 de la LPI. El primero protege el derecho personalísimo tanto desde la captación como en la reproducción, sea o no para puesta en el comercio. Por su parte, el artículo 31 expresamente se limita a la protección del retrato (imagen en sentido amplio) en los casos de puesta en el comercio, indicando cuándo es libre la publicación y quién debe prestar el consentimiento en los casos en los que no es libre (Garsco, 2015).

3. El artículo 53 del CCyC no califica el consentimiento para la captación y reproducción de la imagen, de modo que puede ser expreso o tácito, es decir, se puede inferir de las acciones de la persona. Por el contrario, el artículo 31 de la LPI califica el consentimiento al establecer que deberá ser otorgado en forma expresa. Por ende, siguiendo la línea de la LPI, que es más restrictiva, un consentimiento tácito no sería suficiente para validar la captación y/o reproducción del retrato de una persona. Más allá de eso, para que el consentimiento tácito sea válido, debe reflejar la voluntad inequívoca del titular y resultar de los actos por los cuales se la puede conocer con certidumbre, conforme el artículo 264 del CCyC.

4. Producto de los avances tecnológicos, el artículo 53 del CCyC aporta una visión más comprehensiva de los distintos mecanismos de 
captación de imágenes, lo cual se encuentra alineado con el principio de neutralidad tecnológica. Al utilizar la expresión "de cualquier modo" para calificar la captación o reproducción del retrato y la voz, el CCyC alude a diferentes maneras de reproducir indebidamente la imagen personal sin limitarlo a determinados casos concretos. De esta forma, se amplía la aplicación de la norma a toda reproducción ilegítima de la imagen que pueda hacerse por cualquier medio. Cabe señalar que la propia jurisprudencia anterior a la sanción del CCyC ya había considerado la expresión "retrato fotográfico". Dado que la LPI no contempla dicha especificación, no contradice en absoluto al Código Civil y Comercial al respecto.

5. En el CCyC se detallan de forma más precisa los supuestos de reproducción libre de la imagen personal, es decir, aquellos casos no requieren el consentimiento expreso de su titular. Estos son: (i) cuando la persona participe en actos públicos; (ii) cuando exista un interés científico, cultural o educacional prioritario y se tomen las precauciones suficientes para evitar un daño innecesario; y (iii) cuando se trate del ejercicio regular del derecho de informar sobre acontecimientos de interés general.

6. Respecto a la autorización para reproducir la imagen una vez fallecido el titular, el CCyC confiere el poder de otorgar dicha autorización a los herederos sin establecer los límites que prevé el primer párrafo del artículo 31 LPI. Además, indica que, en caso de discrepancia entre estos, la cuestión se resolverá judicialmente y se incorpora la posibilidad de que el fallecido haya designado a una persona específica para prestar este consentimiento mediante una disposición de última voluntad.

7. Finalmente, en su último párrafo, el CCyC agrega que, transcurridos los veinte ańos desde la muerte del titular de la imagen, la reproducción es libre siempre y cuando se trate de una reproducción no ofensiva.

Por lo expuesto, queda claro que actualmente en Argentina la norma del $\mathrm{CCyC}$ es la que tiene un alcance más actual del derecho a la imagen. Las diferencias existentes entre ambas normas deben ser interpretadas en forma armoniosa para su mejor comprensión y tutela de los intereses de los sujetos titulares de este derecho. 


\section{Protección de la imagen bajo la normativa de protección de datos}

Además de la tutela legal mencionada en los apartados anteriores, es preciso destacar que la normativa argentina referida a la protección de datos personales también debe considerarse como parte del régimen jurídico que protege el derecho a la propia imagen.

En primer lugar, señalamos que el régimen general de la protección de datos está dado por la Ley 25326 (LPDP), sancionada el 4 de octubre de 2000, su Decreto Reglamentario 1558/2001 y las disposiciones y resoluciones emitidas por la Agencia de Acceso a la Información Pública (AAIP), autoridad de control de la LPDP.

Específicamente, el artículo 2 de la LPDP define al dato personal como "información de cualquier tipo referida a personas físicas o de existencia ideal determinadas o determinables". ${ }^{8}$

Teniendo en consideración la definición amplia del término, se considera que la imagen es también un dato personal. $\mathrm{Al}$ respecto, la doctrina ha dicho que la obtención, almacenamiento, conservación y tratamiento de imágenes y sonidos se encuentran sometidos a las disposiciones de la LPDP y su reglamentación y, en consecuencia, dichas operaciones deben satisfacer los principios generales relativos a la protección de los datos personales y las obligaciones allí impuestas (Masciotra, 2004).

Además, en ejercicio de su función de autoridad de contralor de la LPDP, la AAIP ha dictado la Resolución 4/2019, ${ }^{9}$ mediante la cual establece que los registros de imágenes captados por sistemas de video vigilancia constituyen una base de datos en los términos del artículo $2^{\circ}$ de la LPDP. Esta Resolución sigue los lineamientos de la Disposición 10/2015 (texto conforme a la Resolución 15/2018 de la AAIP) emitida por la anterior Dirección Nacional de Protección de Datos Personales, organismo que fue sustituido por la actual AAIP como autoridad de control de la LPDP. En sus considerandos, la Disposición 10/2015 indica que "una imagen o registro fílmico

8 Ley 25326 de Protección de los Datos Personales. Disponible en: http://servicios.infoleg.gob.ar/infolegInternet/anexos/60000-64999/64790/norma.htm.

9 Resolución 4/2019 AAIP. Disponible en: http://servicios.infoleg.gob.ar/infolegInternet/anexos/315000-319999/318874/norma.htm. 
constituyen, a los efectos de la LPDP, un dato de carácter personal, en tanto que una persona pueda ser determinada o determinable". Esta norma aprobó las condiciones de licitud para las actividades de recolección y posterior tratamiento de imágenes digitales de personas con fines de seguridad.

De esta forma, se incluyen a las imágenes como datos personales pasibles de ser objeto de tratamiento o procesamiento, contando así los individuos titulares de la imagen con todos los derechos consagrados en la normativa aplicable. Adicionalmente, considerando las particularidades que tiene la captación de imágenes, no debe pasar por alto que el retrato o video de una persona puede reflejar aspectos que determinen rasgos o cuestiones tuteladas en forma acentuada por la normativa vigente considerando su sensibilidad y/o potencialidad de ser objeto de actos de discriminación. En tal sentido, en la medida en que la imagen pueda constituir un dato sensible, gozará de una protección acentuada conforme el régimen que reconoce la propia LPDP. Tal podría ser el caso de un retrato que permita identificar la raza o etnia de la persona. Cabe recordar que el artículo 2 de la LPDP define a los datos sensibles como aquellos "datos personales que revelan origen racial y étnico, opiniones políticas, convicciones religiosas, filosóficas o morales, afiliación sindical e información referente a la salud o a la vida sexual".

De acuerdo con todo lo mencionado, cabe concluir que el retrato tendría una doble protección: tanto por el lado del derecho a la propia imagen como por el lado del derecho a la protección de los datos personales. Por esto último, estaría sujeto a la protección concedida por el marco legal de la LPDP.

\section{La jurisprudencia reciente en Argentina}

Existe una prolífera actividad judicial que ha analizado y establecido los parámetros y contornos del derecho a la propia imagen. Una voluminosa sucesión de casos han sido resueltos por nuestros tribunales y han permitido sentar una valiosa y fructífera doctrina judicial en la materia.

En cuanto al criterio que ha prevalecido en la jurisprudencia nacional, los magistrados han interpretado las normas referidas al 
asunto bajo estudio en el sentido de solo habilitar la captación y reproducción de las imágenes cuando media consentimiento, salvo que exista una excepción aplicable al caso. Al respecto, la procedencia de alguna de las excepciones a la regla del consentimiento ha sido generalmente interpretada en forma restrictiva, considerando que se encuentra en juego un derecho personalísimo. Por ende, en caso de duda, la interpretación suele ser favorable a la necesidad de obtener la autorización del titular para la captación y reproducción del retrato en pos de garantizar una efectiva tutela al derecho a la propia imagen. Esta línea es la que se ha mantenido a lo largo de los ańos, inclusive con anterioridad a la sanción del CCyC.

Adicionalmente, los jueces han consensuado que la protección del derecho a la propia imagen es independiente de la tutela al honor y a la intimidad, teniendo toda persona un derecho exclusivo sobre ella que se extiende a su utilización, de modo de poder oponerse a su difusión sin su autorización.

En los siguientes párrafos nos abocaremos a analizar cómo la reciente jurisprudencia ha interpretado las normas analizadas en el apartado anterior.

\subsection{Caso S. V. T. c/Google Inc. s/acción preventiva de daños ${ }^{10}$}

En este caso, la demandante había enviado fotografías suyas a una agencia de modelos. Años más tarde, ingresó a trabajar al Senado de la Nación. Fue ahí donde, por comentarios de una compañera, tomó conocimiento de que sus retratos aparecían en varios sitios de internet que eran referidos por el buscador Google. En consecuencia, decidió iniciar una acción de prevención del daño contra Google a fin de que eliminaran las asociaciones de su nombre con los resultados de las búsquedas vinculadas con determinados sitios.

Tanto el juez de Primera Instancia como la Sala II de la Cámara Nacional de Apelaciones en lo Civil y Comercial Federal accedieron al pedido de la actora, por lo que establecieron que debía_procederse a la eliminación y bloqueo de sus fotografías y su vinculación con

10 Cámara Nacional de Apelaciones en lo Civil Comercial, Sala II, S. V. T. cl Google Inc. s/acción preventiva de daños, 03/05/2019, AR/JUR/17970/2019. 
los sitios denunciados. Esto se debió principalmente a que la propia interesada había manifestado que actualmente no existía vigencia en su consentimiento para la difusión de las mencionadas imágenes. De ello se desprende que la autorización para captar la imagen no abarca el uso posterior que no estuviese relacionado directamente con aquella captación originaria, por ende, un nuevo consentimiento del titular es necesario.

Adicionalmente, la Cámara definió al consentimiento como al acto jurídico de naturaleza extrapatrimonial mediante el cual el titular de un derecho autoriza a un tercero para hacer uso de él. De este modo, la regla general sentada en el artículo 55 del CCyC prevé que "[...] este consentimiento no se presume, es de interpretación restrictiva, y libremente revocable”.

\subsection{Caso Mazza, Valeria Raquel c/Yahoo SRL Argentina y otro ${ }^{11}$}

En relación con la actividad de los buscadores y el derecho a la imagen, es importante traer a colación este caso, en el que el voto mayoritario de la Corte Suprema de Justicia (CSJN) mantuvo su criterio vertido en los leading cases Rodríguez, María Belén c/Google Inc. ${ }^{12} \mathrm{y}$ Gimbutas, Carolina Valeria c/Google Inc. ${ }^{13}$

En cuanto al primer caso, en el fallo Rodríguez la CSJN decidió dejar sin efecto la condena a Google Inc., que había operado en instancias inferiores por la utilización de la imagen de la actora (una modelo), al considerar el voto mayoritario que el artículo 31 de la Ley 11723 no es aplicable ante los thumbnails, toda vez que en la cuestión debatida no se trata de determinar la responsabilidad que podría atribuírsele a una página de internet, sino a un mero intermediario cuya única función es servir de enlace (buscadores) (Vaninetti, 2020).

Agregado a ello, destacamos que en este precedente la CSJN determinó que el derecho a la imagen integra el derecho a la privacidad

11 CSJN, Mazza, Valeria Raquel c/Yahoo SRL Argentina y otro s/daños y perjuicios, 24/06/2021.

12 CSJN, Rodríguez, Maria Belén el Google Inc. s/daños y perjuicios, 28/10/2014, Fallos: 337:1174.

13 CSJN, Gimbutas, Carolina Valeria c/Google Inc. s/daños y perjuicios, 12/09/2017, Fallos: 340:1236. 
protegido por el artículo 19 de la Constitución Nacional, estableciendo que dicha norma le otorga al individuo un ámbito de libertad en el cual este puede adoptar libremente las decisiones fundamentales acerca de su persona, sin interferencia alguna por parte del Estado o de los particulares, en tanto dichas decisiones no violen derechos de terceros.

Posteriormente, en la sentencia Gimbutas, la CSJN volvió a reforzar la posición mayoritaria que se había plasmado en la causa Rodríguez al sostener que:

En virtud del modo de funcionamiento de los buscadores de imágenes como el de Google no puede concluirse que la demandada sea responsable de reparar daños como los reclamados. La pretensión de la actora se sustenta en que sus imágenes han sido "captadas" o "reproducidas" por el buscador (art. 53, CCCN) o "puestas en el comercio" (art. 31, ley 11.723) sin su consentimiento, lo que violaría el derecho a la propia imagen tutelado por normas constitucionales y convencionales. Ello no es así: los buscadores de imágenes como el de la demandada no "captan", "reproducen" ni "ponen en el comercio" imágenes en el sentido empleado por los arts. 31 de la ley 11.723 y 53 del CCCN, sino que simplemente facilitan al público usuario de Internet, mediante la indexación y la provisión de un modo de enlace, el acceso a las imágenes "captadas", "reproducidas" o "puestas en el comercio" por otros. (Vaninetti, 2020, p. 166)

Teniendo en consideración el criterio expuesto en los precedentes citados, en el fallo Mazza el máximo tribunal resolvió nuevamente sobre la responsabilidad civil de los buscadores de internet. En este caso, la actora alegaba que se estaban lesionando sus derechos personalísimos, tales como el honor, la dignidad, la intimidad, la imagen y el buen nombre y reclamó, en primer término, el cese definitivo del uso antijurídico de su imagen por parte de los buscadores y la eliminación de las vinculaciones de su nombre con determinados sitios de internet, $y$, en segundo lugar, el resarcimiento de los daños y perjuicios que ese hecho le provocó. En su presentación manifestó que al incluir su nombre en el campo de búsqueda de los buscadores 
Google $^{14}$ y Yahoo ${ }^{15}$ se mostraban como resultados sitios de internet con contenido sexual, pornográfico y actividades vinculadas al tráfico de sexo, todo lo cual resulta incompatible con los sentimientos espirituales, el pensamiento y la línea de conducta de Mazza. Por otra parte, la actora expresó que los resultados de la búsqueda de imágenes suponían, además, un uso no autorizado de su retrato, porque aparecían fotografías con su nombre asociadas a las referidas páginas web de pornografía y de oferta de sexo.

Fue así que, mediante una sentencia dividida, la CSJN decidió seguir los lineamientos de los leading cases. En este sentido, consideró que los buscadores no son responsables del contenido publicado por terceros al que se indexa a través de los motores de búsqueda, ya que ello constituye el ejercicio lícito del derecho a la libre expresión y a la difusión de información. De esta forma, el tribunal volvió a aplicar el criterio de atribución de responsabilidad subjetiva en lugar de factores de atribución objetivos.

Con respecto al uso de los thumbnails, la mayoría de los miembros del máximo tribunal también siguieron los lineamientos de lo resuelto en los casos Rodríguez y Gimbutas, entendiendo que su uso no constituye una violación a disposición legal alguna. Por su parte, la minoría, la cual está reflejada en los votos de los Dres. Maqueda y Lorenzetti, consideró que el derecho a la propia imagen incluye la voluntad del titular de decidir si permite o no la captación o difusión de su imagen por un tercero. Según estos dos magistrados, el derecho a la privacidad implica que nadie puede inmiscuirse en la vida privada de una persona ni violar áreas de su actividad no destinadas a ser difundidas sin su consentimiento. En tal sentido, consideraron que ha quedado acreditado que se utilizaron fotografías de la actora sin su consentimiento expreso o tácito, circunstancia que configura una invasión ilegítima a su esfera íntima que debe ser reparada. En consecuencia, propusieron declarar admisible el recurso extraordinario y confirmar la sentencia apelada.

14 www.google.com.ar.

15 www.yahoo.com.ar. 


\subsection{Caso De la Fuente, Rodrigo Fernando c/Artear SA s/daños y perjuicios $^{16}$}

El reclamante, Rodrigo Fernando de la Fuente, promovió una demanda de daños y perjuicios contra una productora de contenidos que realizaba un programa informativo, a raíz de la publicación de una fotografía suya sin autorización. En el marco de un informe televisivo en el que se difundía una investigación periodística sobre la empresa en la que él era empleado, se había incluido su imagen. Dicha compañía y su dueño habían recibido graves acusaciones vinculadas con lavado de dinero, estafas y defraudaciones millonarias.

En esta decisión de marzo de 2021, la Cámara Nacional de Apelaciones en lo Civil (CNCivil) determinó que la simple exhibición no consentida de la imagen afectaba el derecho que se intentaba proteger por medio del artículo 53 del CCyC. Además, esto generaba por sí un dańo moral representado por el disgusto de ver avasallada la propia personalidad. Ello, sin perjuicio de que, en ciertos casos, pueda importar al mismo tiempo una ofensa a su honor o intimidad. De este modo, se entendió que toda captación de la imagen es ilícita en la medida en que no se cuente con el consentimiento expreso de la persona o se trate de uno de los supuestos excepcionales de reproducción autorizados por el artículo mencionado.

Por otra parte, en el fallo bajo análisis los jueces consideraron que la imagen refería a un evento privado y -la circunstancia de que el accionante se hubiese prestado a fotografiarse- no implicaba autorización para su divulgación. Además, sentenciaron que como no se trataba de una personalidad pública, y aunque hubiese mediado un interés general en la investigación efectuada, el hecho resultaba antijurídico en tanto la reproducción de la imagen era superflua para el fin general invocado.

Finalmente, la CNCivil dispuso que el artículo 53, inciso "b" del CCyC (caso de un interés científico, cultural o educacional prioritario) exige que el medio tome las precauciones suficientes para evitar daños innecesarios. En ese orden, la demandada ni siquiera había

16 Cámara Nacional de Apelaciones en lo Civil, Sala K, De la Fuente, Rodrigo Fernando c/Artear SA s/daños y perjuicios, 16/03/2021, SJA 28/07/2021, 11 con nota de Fernando E. AR/JUR/11830/2021. 
"pixelado" o esfumado el rostro del actor y procedió a propagar su imagen en un primer plano, facilitando su reconocimiento sin mayores inconvenientes.

\subsection{Caso Montaño Ortiz, Lisa María c/Editorial Perfil SA s/daños y perjuicios ${ }^{17}$}

En este, la accionante inició un reclamo contra Editorial Perfil S.A. por daños y perjuicios en relación con la publicación no autorizada de su imagen en el sitio web de la demandada.

En el año 2014, la actora había realizado un álbum fotográfico, ya que en esa época se desempeñaba como modelo gráfica y publicitaria. Posteriormente, la demandada consiguió esas fotografías a través de una fotógrafa que manifestó que las imágenes le pertenecían a una modelo que necesitaba publicidad, pues estaba dando los primeros pasos en esa profesión. Fue así que la editorial las publicó en su sitio web. Como consecuencia de ello, la actora solicitó la eliminación de dicha publicación y una indemnización por los daños y perjuicios ocasionados. Esto se debía a que las imágenes le dificultaban conseguir trabajo como docente y periodista dado que la publicación generaba una imagen que le restaba seriedad a su persona y a su perfil profesional.

La demandada opuso excepción de prescripción argumentando que la accionante decidió quejarse y reclamar recién cuatro años después de que las imágenes fueran publicadas.

Finalmente, la CNCivil admitió la excepción de prescripción y, en consecuencia, rechazó la demanda de daños y perjuicios deducida por Lisa María Montaño Ortiz. Para así decidir, entendió que, por tratarse de una única publicación, aunque permaneciera durante un buen tiempo alojada en el web de la accionada, desde que la imagen fue colgada el daño se exteriorizó y, como consecuencia de ello, la acción quedó expedita. Por ende, la actora podría haber reclamado oportunamente, lo cual no hizo sino ańos más tarde.

Precisamente, sobre el plazo de prescripción en cuestiones de res-

17 Cámara Nacional de Apelaciones en lo Civil, Sala I, Montaño Ortiz, Lisa Maria c/Editorial Perfil SA s/daños y perjuicios, 30/04/2021. 
ponsabilidad extracontractual, los jueces sentenciaron que se computa desde la producción del hecho, porque, al menos como regla, es el momento a partir del cual la responsabilidad existe y da nacimiento a la consiguiente acción para hacerla valer. Por el contrario, si la actora pretendiera sostener que arribó al conocimiento real y efectivo del perjuicio en un momento posterior, y que el cálculo del lapso debía posponerse para esa oportunidad por el lógico juego de las reglas que gobiernan la carga de la prueba, sobre ella recae la acreditación de dicha circunstancia, extremo que ni siquiera fue invocado en este caso.

Además, el tribunal entendió que resulta lógico suponer que la demandante conocía o debía conocer la publicación de la nota y de sus imágenes desde el momento en el que fueron subidas a la página web de la accionada o en tiempo cercano. Resulta inverosímil que alguien que es modelo gráfica y publicitaria se desentienda de la producción fotográfica en la que participó y no realice un seguimiento del uso de las fotografías que la tienen como protagonista, dada la trascendencia que la publicidad y difusión de la propia imagen en los medios y en las redes ostentan en el acceso a una actividad como la mencionada y en su más exitoso desarrollo.

\subsection{Caso N., M. G. c/Kapow SA s/Daños y perjuicios ${ }^{18}$}

En este fallo de mayo de 2021, la CNCivil se refirió al artículo 31 de la LPI por un hecho ocurrido con anterioridad a la entrada en vigencia del CCyC. Concretamente, en este caso se trataba de imágenes en las que se podía visualizar al accionante y a su hijo en un paneo general de varias personas comiendo en un restaurante, imágenes que fueron tomadas libremente sin que trascendiera la identidad del menor, ya que se lo veía de espaldas y cuyo rostro apenas se visualizaba en una toma de perfil, que además se veía en la parte inferior derecha de la pantalla, con escasa nitidez debido al zócalo del programa, y permanecía en pantalla escasísimos segundos, lo que hacía dificultosa la individualización del niño, al menos por terceros.

18 Cámara Nacional de Apelaciones en lo Civil, Sala J, N., M. G. c/Kapow SA s/ Daños y perjuicios, 13/05/2021, AR/JUR/30797/2021. 
Teniendo en consideración lo anterior, los jueces resolvieron que la imagen en análisis debe ser encuadrada dentro de las disposiciones del último párrafo del artículo 31 de la LPI, que dispone que es libre la publicación del retrato cuando se relacione con fines científicos, didácticos y en general culturales, o con hechos o acontecimientos de interés público o que se hubieran desarrollado en público. Sumado a ello, determinaron que se trata de una toma efectuada a fin de ilustrar una nota de interés general relativa a la alimentación saludable, sin que de ningún modo pueda colegirse un propósito tendiente a malinterpretar las circunstancias que determinaron el registro de la imagen. En consecuencia, manifestaron que la imagen de personas alimentándose en un restaurante no tiene por sí misma ninguna connotación negativa y que la finalidad de esta solo tendía a hacer hincapié sobre el tema a tratar.

\subsection{Caso Alzugaray, Mirna Fernanda c/Taraborelli Automobile SA s/daños y perjuicios ${ }^{19}$}

La concesionaria Taraborelli Automobile S.A. realizó una filmación de carácter institucional con el objeto de mostrar a los clientes la forma en la que se trabajaba dentro de la compañía. La actora participó de esta iniciativa. Luego de que terminara su vínculo laboral por renuncia de la empleada en el año 2017, la empresa continuó utilizando públicamente el video con su imagen.

A raíz de ello, la actora inició demanda solicitando el cese inmediato de la utilización de su imagen y la indemnización por su uso no autorizado e indebido a través de las redes sociales. La actora manifestó que jamás autorizó la utilización de su imagen para uso público. A su vez, invocó que la situación le generaba un perjuicio laboral, ya que se encontraba trabajando para una empresa competidora.

Al contestar la demanda, la accionada alegó que había convocado a sus empleados a realizar dos videos institucionales para ser utilizados dentro de la empresa y publicados en redes sociales y que la acto-

19 Cámara Nacional de Apelaciones en lo Civil, Sala A, Alzugaray, Mirna Fernanda c/Taraborelli Automobile SA s/daños y perjuicios, 16/07/2021. AR/ JUR/106167/2021. 
ra había sido una de las personas que habían aceptado la propuesta. Asimismo, la empresa manifestó que en todo momento se les hizo saber que los videos iban a ser utilizados tanto dentro como fuera de la empresa. Adicionalmente, Taraborelli Automobile sostuvo que no bien tomó conocimiento de la disconformidad de la actora, procedió a retirar los videos de las redes sociales.

La CNCivil rechazó la demanda de daños originada por la supuesta utilización indebida de imagen, ya que consideró que dado el análisis de los elementos probatorios -intercambio de correos electrónicos-, no cabía más que concluir que la accionante había prestado su consentimiento para participar en los videos institucionales de su exempleadora. Al respecto, la Cámara agregó que no existe derecho positivo que disponga que el consentimiento deba ser prestado de forma escrita, si no, por el contrario, se admite que la autorización pueda ser de manera escrita, verbal y mediante signos inequívocos, es decir que predomina la libertad de formas.

Sumado a lo anterior, la CNCivil argumentó que toda captación de la imagen es ilícita en la medida en que no se cuente con el consentimiento expreso de la persona o no se trate de uno de los supuestos excepcionales de reproducción autorizados. Además, estableció que la autorización para captar imágenes de una determinada persona no implica necesariamente la autorización para reproducirlas, ya que se trata de dos acciones diferentes que suponen consentimientos independientes.

Sin perjuicio de lo expuesto, la Cámara reconoce que la falta de autorización de parte del retratado generará la responsabilidad de quien difunda la imagen sin su debido consentimiento (artículo 1770 del Código Civil y Comercial), el cual conforme lo dispone el artículo 55 del ordenamiento de fondo "no se presume, es de interpretación restrictiva y libremente revocable". Sin embargo, en este caso existían "serios indicios de que la Sra. Alzugaray prestó su consentimiento a la realización de los videos". Por su parte, según el tribunal, la actora tenía conocimiento de que el vídeo del cual fue partícipe sería exhibido en las diferentes agencias pertenecientes a la emplazada, como así también que sería difundido en sus redes sociales.

En este caso, resultó también importante la actitud desplegada por la demandada, quien dio de baja el contenido al momento de 
tomar conocimiento de la intención de la actora de revocar el consentimiento. En efecto, la CNCivil considera que

la manifestación de la actora al momento de celebrarse la mediación implicó la revocación de su consentimiento para la difusión del video, por lo que la conducta desplegada por la emplazada fue ajustada a la ley, pues de lo contrario hubiese generado algún tipo de daño por el que hubiese estado obligada a responder.

\section{Derecho comparado}

\subsection{Regulación en EE. UU.}

\subsubsection{Primeras aproximaciones}

En primer lugar, el derecho a la imagen fue concebido en los EE. UU. como un derecho ligado íntimamente a la vida privada de los individuos. Esta concepción abarcaba tanto la esfera moral como la patrimonial del derecho a la imagen. En este sentido, se hacía alusión al right of privacy, figura en la que se encasilló la facultad de explotar comercialmente la imagen (Ceballos Delgado, 2011).

Ni la Constitución Federal de 1787 ni sus enmiendas reconocen expresamente ese derecho, sin embargo, la Corte Suprema, a lo largo de una extensa y gradual jurisprudencia, lo ha considerado implícito en diversas enmiendas, como por ejemplo la libertad de asociación incorporada en la Primera Enmienda o la garantía de la Cuarta Enmienda frente a registros y requisas arbitrarias, que limita la intrusión del Gobierno en las personas, domicilios, documentos y efectos personales, incluyéndose no solo los supuestos de invasión material, sino también de vigilancia electrónica (Saldaña, 2011).

No obstante, resulta necesario destacar que Samuel D. Warren y Louis D. Brandeis fueron los primeros en hacer referencia a este derecho cuando en 1890 escribieron y publicaron un artículo en la Harvard Law Review titulado "The Right to Privacy", en el que abogaban por el "derecho a ser dejado en paz" (Warren y Brandeis, 1890). Dicho artículo surgió como reacción frente a la divulgación indiscriminada de información privada por parte de la prensa. En ese artículo, los autores afirmaban que impedir su publicación es solo un ejemplo del derecho más general del individuo a no ser molestado, defendiendo 
un derecho a la privacidad que le otorga a toda persona plena disponibilidad para decidir en qué medida pueden ser comunicados a otros sus pensamientos, sentimientos y emociones (Saldańa, 2011).

El primer pronunciamiento judicial en hacerse eco del trabajo de Warren y Brandeis fue el caso Schuyler v. Curtis, ${ }^{20}$ que se originó en ocasión del conflicto suscitado en torno a si era legítimo o no desde el punto de vista del right to privacy que la Woman's Memorial Fund Association erigiera unas estatuas de la fallecida Mary Hamilton Schuyler, sin el consentimiento de su familia, en conmemoración por sus labores altruistas y de beneficencia. El juez Gray, en su voto en disidencia, sostuvo que Philip Schuyler, en su condición de representante de la familia, estaba totalmente legitimado para preservar que se levantaran estatuas de la señora Schuyler, pues la conducta de la asociación suponía exhibirla públicamente, una inmoralidad y una flagrante vulneración del derecho a la intimidad, cuyo manto no podía solo cubrir a la propia persona, sino que debía extenderse a todos los intereses personales, entre los que se encontraba el que sus allegados pudieran preservar la intimidad que en vida había profesado (De las Heras Vives, 2018).

Otro de los incipientes pronunciamientos que recogió expresamente los postulados de Warren y Brandeis fue el de Marks v. Jaffa en 1893, en el que el juez McAdam resolvió que ningún periódico o institución tiene derecho a utilizar el nombre o la imagen de una persona sin su consentimiento, pues todas tienen derecho a disfrutar de la vida sin invasiones en su esfera más personal, de manera que los tribunales debían garantizar el derecho a no ser molestado (De las Heras Vives, 2018).

Contrariamente a lo expuesto y aun cuando en primera y segunda instancia los jueces habían reconocido la existencia de un derecho a la intimidad, en el caso Roberson v. Rochester Folding Box Co, en 1902, el Tribunal de Apelaciones de Nueva York votó por mayoría (cuatro votos a tres) a favor de la inexistencia del derecho a la intimidad. Este caso versaba sobre Abigail M. Roberson, que, en ese entonces, era una adolescente de la ciudad de Rochester que se había

20 Corte de Apelaciones del estado de Nueva York, Schuyler v. Curtis, 42 N.E. 22 (N.Y. 1895). 
retratado en un estudio fotográfico local. Sin saber cómo, su imagen terminó siendo publicada sin su consentimiento en más de veinticinco mil litografías publicitarias tituladas Flour of the Family con su rostro de perfil en primer plano y con el logotipo de la empresa Franklin Mills Flour en la parte inferior (Figura 1). Mucha gente la reconoció y esto le provocó una gran humillación y un severo shock nervioso (Harvard University Press Blog, 2011).

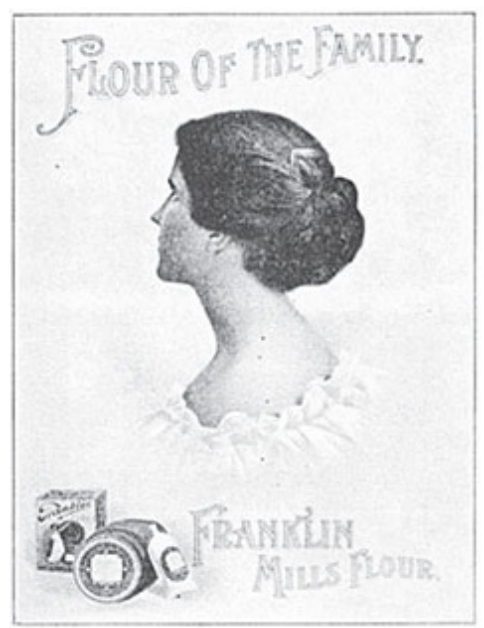

Figura 1. Flour of the Family (fuente: Harvard University Press Blog, 2011).

En primer lugar, los jueces del Tribunal consideraron que el right to privacy no se encontraba reconocido en el common law, puesto que no había sido mencionado por ninguno de los grandes comentaristas ni sostenido en ningún precedente anterior; $y$, en segundo lugar, que dicho reconocimiento supondría una avalancha de litigios, muchos de ellos absurdos (De las Heras Vives, 2018).

Este fallo trajo arduas discusiones y polémicas entre miembros de la prensa, lo cual arrojó como resultado que en 1903, en la sesión legislativa de la cámara del estado de Nueva York, se adoptaran medidas que regularan la protección del uso del nombre e imagen personal con fines publicitarios. Las normas que fueron aprobadas en la mencionada sesión legislativa de Nueva York se plasmaron en las secciones 50 y 51 de la Ley de Derechos Civiles del Estado de Nueva York (Ceballos Delgado, 2011). 
Teniendo en cuenta los antecedentes citados y otros que fueron ocurriendo, el right to privacy fue reconocido por primera vez por la Corte Suprema de los Estados Unidos en 1965 en el caso Griswold v. Connecticut, ${ }^{21}$ cuando se declaró la inconstitucionalidad de una norma estatal que prohibía la venta y utilización de anticonceptivos por considerarla lesiva del "derecho fundamental a la privacidad". Para la Corte, este derecho derivó de las llamadas "zonas de penumbras” emanadas por específicas garantías reconocidas en la Carta de Derechos de los Estados Unidos (Saldaña, 2011). De esta forma, consideró al derecho a la intimidad como un derecho constitucional autónomo e independiente que deriva de la propia normativa norteamericana.

\subsubsection{Aparición del right of publicity}

Como hemos visto, la protección de la intimidad llegó por vía jurisprudencial y doctrinal, considerando que esta podía verse vulnerada por actos de divulgación de la imagen o vida privada de una persona determinada. De igual forma fue que nació el right of publicity, cuya expresión y teoría aparecieron por primera vez en el caso Haelan Laboratories, Inc. v. Topps Chewing Gum ${ }^{22}$ del 16 de febrero de 1953, en el que un jugador de béisbol había firmado un contrato con la demandante que le otorgaba el derecho exclusivo a utilizar su fotografía en relación con una goma chicle fabricada por la demandada. El jugador se había comprometido a no ceder el derecho de uso de su fotografía a ningún otro fabricante de golosinas. La demandada, conociendo el contrato de Haelan, convenció al jugador para que firmara un contrato que le permitiera a Topps utilizar la fotografía del jugador en relación con su chicle. Se planteó la validez del contrato firmado con Haelan ante la Corte de Apelaciones del Segundo Circuito.

El tribunal decidió que, además del derecho de privacidad, una persona tiene un derecho sobre el valor de publicidad de su fotogra-

21 Corte Suprema de los Estados Unidos, Griswold v. Connecticut, 381 U.S. 479 (1965).

22 Corte de Apelaciones de los Estados Unidos, Segundo circuito, Haelan Laboratories, Inc. v. Topps Chewing Gum, Inc., 202 F.2d 866 (2d Cir. 1953). 
fía, derecho que es válido independientemente de que implique o no la transferencia de este a través de un negocio. Este derecho fue llamado right of publicity, el cual fue considerado de carácter patrimonial y, por tanto, trasmisible (Ceballos Delgado, 2011).

Fue así que, a mediados del siglo XX, se desarrolló el derecho en cuestión como una rama separada y como contracara del right to privacy. El right of publicity fue concebido como la facultad exclusiva de explotación comercial del nombre o de la imagen comercial de la persona, en la que lo que se buscaba no era reparar un dańo por intromisión en la privacidad por la difusión de la imagen de la persona, sino una indemnización por el aprovechamiento comercial de la imagen susceptible de valorarse en el mercado (Nogueira Alcalá, 2007).

Actualmente, no existe un right of publicity federal en EE. UU., sin embargo, el tribunal supremo ha determinado que la Primera Enmienda (libertad de expresión) no impide que la legislación estatal contemple la posibilidad del afectado de entablar una reclamación por la apropiación comercial de la identidad. En diversos estados se ha reconocido y admitido este derecho. En consecuencia, el uso del nombre o la imagen de una persona, al menos en la publicidad, puede ser objeto de un reclamo (Kurnit, 2019).

Respecto a los aspectos de la identidad de una persona que se encuentran protegidos por este derecho, encontramos los siguientes: el nombre, la imagen, el retrato, la semejanza, la voz, la firma y los gestos (Kurnit, 2019).

En vista de todo lo expuesto, podría decirse que la protección y el resguardo al derecho a la imagen en EE. UU. se configuran con y por la complementación de una doble vía que comprende tanto el right to privacy como el right of publicity. De esta forma, por un lado se resguarda el derecho a gozar de una esfera privada y, por el otro, se consagra el derecho a la libertad de decisión sobre la explotación económica de la imagen.

\subsection{Regulación en Europa. El caso de Portugal y España}

Primeramente, debe decirse que a nivel comunitario el derecho a la imagen no se encuentra previsto en una normativa concreta. En este sentido, el Convenio Europeo de Derechos Humanos de 1950 no 
recoge el derecho en cuestión, pero sí prevé el derecho al respecto a la vida privada y familiar en su artículo 8 . No obstante, en su jurisprudencia, el Tribunal Europeo de Derechos Humanos lo ha situado como parte de dicho artículo, ya que lo entiende como una manifestación a la protección a la vida privada, adquiriendo así el carácter de derecho humano (Moraleda Gómez, 2020).

No obstante, corresponde destacar que este derecho sí fue recibido por diversos países europeos en sus ordenamientos internos. Particularmente, respecto a sus orígenes en el derecho positivo del continente en cuestión, debemos remontarnos a la ley alemana de fotografía de enero de 1876, a la normativa sobre propiedad intelectual y artística de Austria de 1885, seguida por la ley belga sobre el derecho de autor del 22 de marzo de 1886 (artículo 20). Dentro de este contexto, se ha afirmado que es un derecho que se fortaleció en la década de 1950, cuando empezó la concreción jurídico-constitucional de los derechos humanos de la Declaración Universal de 1948 (Rodrigues da Cunha e Cruz, 2009).

\subsubsection{España}

La Constitución española de 1978 (CE) inaugura la protección constitucional expresa del derecho a la propia imagen con la inserción de la palabra "imagen" en la redacción del artículo 18.1. Además, fue la primera en configurarlo como un derecho autónomo (Rodrigues da Cunha e Cruz, 2009).

Agregado a ello, el derecho se encuentra contemplado en la Ley Orgánica 1/1982, del 5 de mayo, sobre protección civil del derecho al honor, a la intimidad personal y familiar y a la propia imagen. ${ }^{23}$ Concretamente, según el artículo 1.3, junto con el derecho al honor, a la intimidad personal y familiar, se trata de un derecho "irrenunciable, inalienable e imprescriptible. La renuncia a la protección prevista en esta ley será nula, sin perjuicio de los supuestos de autorización o consentimiento a que se refiere el artículo segundo de esta ley”.

Seguidamente, el artículo 7.5 establece que se constituyen_intro-

23 Ley Orgánica 1/1982. Disponible en: https:/www.boe.es/buscar/act. php?id=BOE-A-1982-11196. 
misiones ilegítimas "la captación, reproducción o publicación por fotografía, filme o cualquier otro procedimiento, de la imagen de una persona en lugares o momentos de su vida privada o fuera de ellos, salvo los casos previstos en el artículo 8.2".

Por su parte, el artículo 7.6 dispone que se considerará intromisión ilegítima "la utilización del nombre, de la voz o de la imagen de una persona para fines publicitarios, comerciales o de naturaleza análoga”.

El artículo 8.2 determina que, en particular, el derecho a la propia imagen no impedirá

a) Su captación, reproducción o publicación por cualquier medio cuando se trate de personas que ejerzan un cargo público o una profesión de notoriedad o proyección pública y la imagen se capte durante un acto público o en lugares abiertos al público; b) La utilización de la caricatura de dichas personas, de acuerdo con el uso social; c) La información gráfica sobre un suceso o acaecimiento público cuando la imagen de una persona determinada aparezca como meramente accesoria. Las excepciones contempladas en los párrafos a) y b) no serán de aplicación respecto de las autoridades o personas que desempeñen funciones que por su naturaleza necesiten el anonimato de la persona que las ejerza.

Al igual que en otras jurisdicciones, en España este derecho se vincula con la esfera personal del individuo, ya que se entiende que le es inherente por el mero hecho de ser persona. Es así que se encuentra ineludiblemente unido a la dignidad personal, la que también está recogida en su texto constitucional, concretamente en el artículo 10. Esto demuestra que estamos ante un derecho de los denominados "personalísimos" (Villanueva-Turnes, 2016).

La característica más notable y relevante del estudio del derecho en cuestión en España es su bipartición en dos contextos bien distintos: el moral y el patrimonial. Tanto la jurisprudencia como la doctrina española hacen una clara diferencia entre el ámbito constitucional del derecho a la propia imagen y el ámbito patrimonial-civil que el derecho a la propia imagen puede tener (Rodrigues da Cunha e Cruz, 2009).

En tal sentido, el derecho constitucional a la propia imagen es de carácter moral y comprende el derecho que se tiene a que los rasgos 
físicos que distinguen al individuo de los demás no sean divulgados sin su consentimiento, mientras que el derecho patrimonial a la propia imagen es la proyección estrictamente económica, material, simplemente pecuniaria. Es el derecho subjetivo patrimonial que tiene protección infraconstitucional; se trataría de la dimensión legal, supuestamente un derecho de propiedad intelectual más (López Mingo Tolmo, 2005, como se citó en Rodrigues da Cunha e Cruz, 2009).

En cuanto a su finalidad, ciertos autores entienden que es proteger la dimensión pública de las personas, impidiendo tanto la obtención de imágenes del titular del derecho como su reproducción o publicación. A efectos de su vulneración, este derecho va a actuar con independencia de la finalidad que tenga la conducta infractora. Esto se debe a que, en caso de exigirse que la imagen se hiciese pública o se reprodujese en cualquier lugar para que se configure la vulneración, supondría que el simple hecho de obtenerla no sería una vulneración del derecho en sí, cuando es posible que la imagen se quiera para un uso personal no deseado por el titular del derecho. Por lo tanto, la finalidad de la conducta infractora debe resultar totalmente irrelevante a los efectos de determinar si hubo infracción o no (Villanueva-Turnes, 2016).

En la Sentencia 81/2001 de 26 de marzo de $2001^{24}$ del Tribunal Constitucional de España, se delimita el ámbito de protección constitucional de tal derecho; puntualmente los jueces han dicho que

lo que se pretende con este derecho, en su dimensión constitucional, es que los individuos puedan decidir qué aspectos de su persona desean preservar de la difusión pública, a fin de garantizar un ámbito privativo para el desarrollo de la propia personalidad ajeno a injerencias externas. ${ }^{25}$

Adicionalmente, en la sentencia citada ut supra, el Tribunal Constitucional ha dicho que la protección de los valores económicos, pa-

24 Disponible en: http://hj.tribunalconstitucional.es/HJ/es/Resolucion/ Show/4377.

25 Doctrina que se sigue en la STC 156/2001, de 2 de julio, FJ6, y STC 83/2002, de 22 de abril, FJ4 (Rodrigues da Cunha e Cruz, 2009, p. 36). 
trimoniales o comerciales de la imagen afectan a bienes jurídicos distintos de los que son propios de un derecho de la personalidad y, por ello, aunque dignos de protección y efectivamente protegidos, no forman parte del contenido del derecho fundamental a la propia imagen del artículo 18.1 CE (Nogueira Alcalá, 2007).

Dicho lo anterior, se entiende que la especial garantía constitucional frente a sus posibles vulneraciones se sustancia, por un lado, en la existencia de un específico procedimiento de protección civil, basado en los principios de sumariedad y preferencia, y, por otro, en el recurso de amparo ante el Tribunal Constitucional. Las vías de protección señaladas permitirán diferenciar entre las dimensiones patrimonial y moral del derecho, de forma que, correspondiendo a la jurisdicción ordinaria la defensa de ambas, la segunda resultaría propia del ámbito de competencias del Tribunal Constitucional (De Lamo Merlini, s.f.). Sin embargo, la clasificación expuesta no impedirá que, como el propio Tribunal Constitucional español advierte, la utilización comercial de la imagen de una persona sin su consentimiento siga constituyendo una vulneración del derecho fundamental. La captación, reproducción o publicación sin consentimiento de la imagen de una persona, con independencia de su finalidad, constituye, en principio, una vulneración del derecho fundamental a la propia imagen, ya que con ello se está interfiriendo en el ámbito de libre determinación individual amparado por este (Rodrigues da Cunha e Cruz, 2009).

Dicho todo lo anterior, cabe mencionar que esta diferenciación existente en Espańa se hace necesaria para fines teóricos y prácticos. Teóricos, porque delimita el campo conceptual de cada aspecto del derecho a la propia imagen, en tanto que en el terreno procesal, el Tribunal Constitucional español únicamente se manifiesta respecto al derecho a la propia imagen en su vertiente constitucional/negativa, no siendo susceptible de amparo la dimensión patrimonial ante el mencionado tribunal y situándose por fuera de la protección constitucional del artículo 18.1 de la CE (Rodrigues da Cunha e Cruz, 2009).

En cuanto al ámbito penal, el Código en cuestión tipifica los "Delitos contra la Intimidad, el derecho a la propia imagen y la inviolabilidad de domicilio" en el Título X del Libro II, artículos 197 a 204. No obstante la autonomía dada al derecho a la propia imagen, 
lo que esta norma tutela es, en realidad, la intimidad de la persona a fin de que no sean conocidos determinados hechos que solo son conocidos por ella o por un círculo reducido.

Más allá de lo desarrollado anteriormente, es preciso mencionar que la legislación española, en materia de protección de datos personales, también tutela el derecho a la imagen. Esto se debe a que, para la normativa en cuestión, se va a considerar dato personal toda información sobre una persona física identificada o identificable; es por ello que la imagen de una persona es considerada un dato personal.

Específicamente, el derecho a la protección de los datos personales se encuentra reconocido en el artículo 18.4 de la CE y en la Ley Orgánica 3/2018 de Protección de datos de Carácter Personal y Garantía de los Derechos Digitales (LOPDGDD), que tiene por objeto adaptar y regular en su ordenamiento jurídico interno lo dispuesto en el Reglamento (UE) 2016/679 del Parlamento Europeo y del Consejo, de 27 de abril de 2016, relativo a la Protección de las Personas Físicas en lo que respecta al tratamiento de datos personales y a la libre circulación de estos datos (RGPD). Inclusive, dentro del catálogo de definiciones que contempla el RGPD en su artículo 2, se define a los "datos biométricos" como datos personales obtenidos a partir de un tratamiento técnico específico relativos a las características físicas, fisiológicas o conductuales de una persona física que permitan o confirmen la identificación única de dicha persona, como imágenes faciales. $\mathrm{Al}$ respecto, los datos biométricos son considerados como una categoría especial de datos personales y sujeto a un régimen más estricto.

\subsubsection{Portugal}

El derecho a la propia imagen se encuentra previsto en la Constitución de la República Portuguesa (CRP) de 1976. Su protección formal expresa apareció en la primera revisión constitucional de 1982, concretamente, en la nueva redacción que se le dio al entonces artículo 33 de la CRP (actual artículo 26.1) (Rodrigues da Cunha e Cruz, 2009). La norma dispone que 
Todos tienen el derecho a la identidad personal, al desarrollo de su personalidad, a la capacidad civil, a la ciudadanía, a su buen nombre y reputación, a su imagen, a su expresión, a proteger la privacidad de su vida personal y familiar y a la protección legal contra cualquier forma de discriminación.

Sumado a lo anterior, el Código Civil $^{26}$ regula esta materia en su artículo 79 y establece que

El retrato de una persona no podrá ser expuesto, reproducido o lanzado al comercio sin el consentimiento de ésta; después de la muerte del retratado, la autorización se concederá a las personas designadas en el número 2 del artículo 71, en el orden indicado en el mismo.

\section{A su vez,}

No será necesario el consentimiento de la persona retratada cuando lo justifique su notoriedad, el cargo que ostente, las exigencias policiales o judiciales, los fines científicos, educativos o culturales, o cuando la reproducción de la imagen se enmarque en la de lugares públicos, o en la de hechos de interés público o que hayan tenido lugar en público.

Por último, "el retrato [no obstante] no podrá ser reproducido, expuesto o lanzado al comercio cuando el hecho cause un perjuicio al honor, a la reputación o al simple decoro de la persona retratada”.

Al mismo tiempo, para la doctrina, el derecho a la imagen se configura como un bien jurídico-penal autónomo, tutelado en sí mismo y por sí mismo, independientemente de su valor desde el punto de vista de la privacidad/intimidad. La imagen es un elemento/bien jurídico eminentemente personal con la estructura de una libertad fundamental y que le reconoce a la persona el dominio exclusivo de su propia imagen (Pereira et al., s.f.).

26 Código Civil de Portugal. Disponible en: http://bdjur.almedina.net/item. php?field=item_id $\&$ value $=366531$. 
En línea con ello, el Código Penal ${ }^{27}$ castiga como delito las grabaciones y fotografías ilícitas, es decir, aquellas cuya divulgación es en contra de la voluntad de su titular. Por consiguiente, cada persona tiene la facultad de prestar su consentimiento y decidir cuándo será fotografiada o filmada y cuándo podrán utilizarse esas fotografías o filmaciones. El derecho constitucional portugués entiende que para ser protegida la imagen humana debe ser configurada a través de tres criterios que se interrelacionan: la individualidad, la visibilidad y la recognoscibilidad. En este sentido, la imagen debe ser entendida como la proyección del aspecto físico externo de la persona y el mensaje visual de su contenido se realiza a través de la representación gráfica material de los aspectos inmateriales de la personalidad (Trabuco, 2001, como se citó en Rodrigues da Cunha e Cruz, 2009).

En línea con lo anterior, el derecho portugués pretende proteger un bien jurídico eminentemente personal, que tiene estructura de libertad fundamental y que le otorga al titular el dominio sobre la propia imagen, de modo que es el titular del derecho el que determina quién y en qué medida puede registrarla o divulgarla (Andrade, 1996, como se citó en Rodrigues da Cunha e Cruz, 2009).

Por último, destacamos que la doctrina de Portugal no está en desacuerdo con la opinión general de que el derecho a la propia imagen se desarrolla en sus dos vertientes: la positiva (patrimonial) y la negativa (material). Al respecto, estiman que la potencia patrimonial del derecho a la propia imagen sí está dentro del concepto constitucional puesto de manifiesto por el constituyente de 1976. Esto se debe, entre otras causas, a que el propio contexto progresista interpretativo de la CRP se inclina en este sentido, pues existe una clara preocupación constitucional de proteger al derecho como un todo, abarcando todas las posibilidades de lesión que puedan surgir (Rebelo, 1998, como se citó en Rodrigues da Cunha e Cruz, 2009). $\mathrm{Al}$ igual que en el caso de Espańa, debemos decir que la normativa relativa a la protección de datos de las personas también ampara el

27 Código Penal de Portugal. Disponible en: https://europam.eu/data/mechanisms/PF/PF\%20Laws/Portugal/Portugal_criminal\%20code_1982_ amended2015_por.pdf. 
derecho a la imagen. En el caso de Portugal, la Ley 58/2019 garantiza la aplicación en la legislación nacional del RGPD y, así, la protección de la imagen de los individuos como dato personal.

\section{Conclusión}

Conforme con lo que se ha analizado a lo largo de todo este trabajo, el derecho a la imagen se encuentra íntimamente vinculado con los derechos personalísimos de los individuos. Tal es así que, más allá de ciertas diferencias en las legislaciones de cada territorio, los cuerpos normativos de los países coinciden es sus principales aspectos y caracteres; estos lo consagran y reconocen otorgándole, en ciertos casos, un reconocimiento expreso en su texto constitucional.

En el caso de Argentina, y a diferencia de lo que sucede en Espańa y Portugal, no se ha incorporado en forma expresa una referencia al derecho a la propia imagen. Sin perjuicio de ello, la tutela estaría garantizada a través de los principios constitucionales que amparan la privacidad e intimidad de las personas, así como las leyes sancionadas a la fecha que le dan protección a la imagen de las personas.

A lo largo del tiempo, la concepción de este derecho se ha ido adaptando y modificando, de forma tal que pueda comprender los escenarios que fueron surgiendo, como, por ejemplo, con la irrupción de las nuevas tecnologías y las últimas formas de captar imágenes. En este sentido, consideramos que este derecho debe entenderse e interpretarse como un derecho dinámico y en constante actualización. Para ello, una visión tecnológicamente neutral es la vía adecuada para regular el instituto.

Adicionalmente, concluimos que, como tantos otros, el derecho a la propia imagen debe evaluarse haciendo una correcta ponderación de las circunstancias de cada caso concreto y teniendo en consideración otros derechos de especial importancia, como el derecho a la libertad de expresión y el acceso a la información.

Siguiendo estos parámetros es que podemos contar con un sistema de derecho más justo, en el que prima el equilibrio entre los distintos intereses y derechos de los individuos que lo componen. 


\section{Bibliografía}

Barbieri, P. C. (2014). Derecho a la imagen personal en el nuevo Código Civil y Comercial: un paso adelante. http://www.saij.gob.ar/pablo-carlos-barbieri-derecho-imagen-personal-nuevo-codigo-civil-comercial-paso-adelante-dacf140 721-2014-10-02/123456789-0abc-defg1270-41fcanirtcod.

Cabello, M. (2018). El derecho a la imagen y el contrato de trabajo actoral. Anales de Legislación Argentina, (10), 111-116. AR/DOC/1228/2018.

Ceballos Delgado, J. M. (2011). Aspectos generales del derecho a la propia imagen. Revista La propiedad inmaterial, (15), 61-83. https://dialnet.unirioja.es/ servlet/articulo?codigo $=3785211$.

De las Heras Vives, L. (2018). La intimidad en crisis: repensando su finalidad. Rev. Boliv. de Derecho, (26), 78-107. http://idibe.org/wp-content/ uploads/2018/08/78-107.pdf.

De Lamo Merlini, O. (s.f.). Consideraciones sobre la configuración del derecho a la propia imagen en el ordenamiento español. Universidad Complutense de Madrid. https://eprints.ucm.es/id/eprint/10972/1/Lamo_Merlini_derecho_a_ la_propia_imagen.pdf.

Garsco, M. A. (2015). El nuevo Código Civil y Comercial, respecto del microsistema de la propiedad intelectual. Revista Código Civil y Comercial, AR/ DOC/3259/2015.

Harvard University Press Blog. (2 de agosto de 2011). Who Owns Your Face? https://harvardpress.typepad.com/hup_publicity/2011/08/who-owns-yourface.html.

Kurnit, R. (2019). Right of Publicity in the USA. Lexology. https://www.lexology. com/library/detail.aspx?g=8b163135-9c21-4448-9a65-e25382113139.

Lamm, E. (2017). Derecho a la imagen. Ministerio de Salud, Presidencia de la Nación. https://salud.gob.ar/dels/entradas/derecho-la-imagen.

Masciotra, M. (28 de abril de 2004). La voz y la imagen y el ámbito de aplicación de la ley de protección de datos personales. Sistema Argentino de Información Jurídica. http://www.saij.gob.ar/mario-masciotra-voz-imagen-ambito-aplicacion-ley-proteccion-datos-personales-dacf040044-2004-04-28/123456789-0 abc-defg4400-40fcanirtcod.

Moraleda Gómez, M. (2020). El derecho al honor, a la intimidad personal y familiar $y$ a la propia imagen en el s. XXI (Tesis de maestría). Colegio Universitario de Estudios Financieros, Madrid. https://biblioteca.cunef.edu/files/documentos/ TFM_Mercedes_Moraleda_Gomez.pdf.

Nogueira Alcalá, H. (2007). El derecho a la propia imagen como derecho fundamental implícito. Fundamentación y caracterización. Revista Ius Et Praxis, 13(2), 245-285. https://scielo.conicyt.cl/pdf/iusetp/v13n2/art11.pdf.

Pereira, D. Silva, Paulino Alves, C. y Ferreira, T. (s.f.). O direito à imagem: toda a imagem tem o seu preço. http://carlospintodeabreu.com/wp-content/ uploads/2018/10/35_societario_direito_imagem.pdf.

Rodrigues da Cunha e Cruz, M. A. (2009). El concepto constitucional del dere- 
Instantáneas sobre el derecho a la propia imagen. Un análisis de la legislación y jurisprudencia actual...

cho a la propia imagen en Portugal, España y Brasil. Araucaria. Revista Iberoamericana de Filosofía, Politica y Humanidades, 11(22), 17-50. https://idus. us.es/handle/11441/46051.

Saldaña, M N. (2011). El derecho a la privacidad en los Estados Unidos: aproximación diacrónica a los intereses constitucionales en juego. Teoría y Realidad Constitucional, (28), 279-312.

Vaninetti, H. A. (2020). Derecho a la intimidad en la era digital (1 a ed., Vol. 1). Hammurabi. https://biblioteca.hammurabidigital.com.ar/reader/derecho-a-laintimidad-en-la-era-digital-vol-1 location=166.

Villanueva-Turnes, A. (2016). El derecho al honor, a la intimidad y a la propia imagen, y su choque con el derecho a la libertad de expresión y de información en el ordenamiento jurídico espańol. Díkaion, 25(2), 190-215. https://www. redalyc.org/journal/720/72048894003/html/.

Warren, S. D. y Brandeis, L. (1890). The Right to Privacy. Harvard Law Review, IV(5). http://groups.csail.mit.edu/mac/classes/6.805/articles/privacy/Privacy_brand_ warr2.html. 